\title{
EFECTOS SOBRE EL EMPLEO DE LA REDUCCIÓN DEL TIEMPO DE TRABAJO: APRENDIZAJES DE LA EXPERIENCIA FRANCESA ${ }^{1}$
}

\author{
Mikel de la Fuente Lavín \\ Jon Bernat Zubiri Rey \\ Euskal Herriko Unibertsitatea / Universidad del País Vasco (UPV/EHU)
}

DOI: $10.1387 /$ lan-harremanak. 16558

ABSTRACT

En este artículo trataremos de aportar algunos elementos de diagnóstico de la politica de reducción del tiempo de trabajo (RTT) en Francia. Tras comprobar el mal reparto de los aumentos de productividad de las últimas décadas, tanto en España como en Euskal Herria y Francia, nos sumergiremos en la experiencia francesa, partiendo de los precedentes que dieron lugar a una apuesta de RTT a priori diseñada para ser progresivamente generalizada. Expondremos la mecánica básica de Leyes Aubry (1998-2000) y especialmente la obligación de RTT en todas las empresas del sector mercantil de más de 20 asalariados a partir del 1 de enero del 2000. Haremos mayor hincapié en una valoración crítica de los efectos de estas dos leyes sobre la duración de las jornadas, el empleo y los salarios. Abordaremos las evoluciones posteriores de regresión sarkozysta en las políticas de RTT, asi como la "última vuelta de tuerca» del Gobierno "socialista» de Valls, en actual liza contra un movimiento social y sindical de alto calado. El objetivo de este artículo es hacer un balance del

${ }^{1}$ La autoría de este artículo está indicada por orden alfabético, justificada en el trabajo equitativamente compartido de análisis del reparto del tiempo de trabajo, en el marco del Proyecto de Investigación «Reparto del empleo y del tiempo de trabajo: efectos en la fiscalidad y tratamiento jurídico», financiado por el Departamento de Innovación de la Diputación Foral de Gipuzkoa, a ejecutar entre el 22-12-2014 y el 30-10-2015. 
pasado de la experiencia francesa, tratando de conectarla con nuestra vocación de importar sus enseñanzas a nuestra realidad concreta.

Palabras clave: tiempo de trabajo, reducción del tiempo de trabajo, Francia, Leyes Aubry.

In this article we will provide some elements of diagnosis of Working Time Reduction (WTR) policies in France. We will start by establishing the unequal share of productivity increases in recent decades in Spain and in the Basque Country as well as in France. Next we will focus on the French experience, starting with the precedents that gave rise to an initial WTR proposal designed to be implemented gradually on a general basis. We will explain the basic procedure outlined in Aubry Laws (1998-2000) and particularly the obligation to implement a WTR on the part of all companies and businesses in the trade sector with over 20 employees as from Jan 1 2000. We will place higher emphasis on a critical assessment of the effects of these two laws on daily working hours, employment and pay. We will also address the subsequent Sarkozy-type regressive evolution in WTR policies, as well as the last twist in the so-called Socialist Valls Government, currently at odds with a strong social and trade union movement. The aim of this article is to take stock of the past of the French experience, trying to connect it with our desire to apply its lessons to our specific reality.

Keywords: working time, working time reduction, France, Aubry Laws.

Artikulu honetan Frantziako lanaldiaren murrizketari buruzko politikaren diagnosi-elementuak ematen saiatuko gara. Azkeneko hamarraldietan, Espainian, Euskal Herrian eta Frantzian egondako emankortasunaren igoeren banaketa desegokia ikusi ondoren, esperientzia frantzesan murgilduko gara hasieran progresiboki hedatzeko diseinatutako lanaldi murrizketaren aldeko aurrekariak abiapuntutzat harturik. Aubry Legeen (1998-2000) oinarrizko mekanika azalduko dugu eta batez ere, 2000ko urtarrilaren letik aurrera, merkatal sektoreko 20 langile baino gehiagoko enpresek lanaldia murrizteko duten betebeharra. Lege horiek jardunaldian, enpleguan eta soldatan izan duten eraginaren balorazio kritikoa nabarmenduko dugu. Gerora, lanaldiaren murrizketan gertatutako atzerakada sarkozysta azalduko dugu eta, baita ere, gizarte mugimenduekin eta mugimendu sindikalekin lehian ari den Vall-en Gobernu "sozialistaren" estu hartzea. Artikuluaren helburua da Frantziaren iraganeko esperientziaren balorazioa egitea eta bertatik ikasitakoa gure errealitatera inportatu.

Hitz gakoak: lan-denbora, lanaldiaren murrizketa, Frantzia, Aubry Legeak. 


\section{Presentación}

Cómo hemos argumentado en De la Fuente y Zubiri (2016a) y seguimos profundizando en Castrillón et al. (2016c; 2016d), la Reducción del Tiempo de Trabajo (RTT) con mantenimiento de salarios exige un reequilibrio del reparto de los incrementos de productividad, que durante las últimas décadas han ido a parar a los beneficios empresariales, en detrimento de los salarios. La RTT es una vía eficaz, poco tenida en cuenta en el actual debate económico y laboral, pero que puede ser una potente herramienta para contrarrestar la evolución negativa que se ha producido en las últimas décadas en la "parte salarial» del PIB en beneficio del excedente empresarial. En Espańa, este ratio pasa del 78\% en 1980 al 70,6\% en 1990 y al 66,9 en 1998, es decir una reducción de 10,6 puntos, superior al medio de la UE, que pasó del 76,0 en 1980 al 70,9 en 1990 y al 68, 2 en 1998, con una reducción de 7,8 puntos (Eurostat). Más recientemente, el peso de las rentas del trabajo en el PIB ha pasado desde 2010, tanto en España como en Hego Euskalerria, por debajo de la barrera simbólica del 50\%, a favor de las rentas del capital (ELA, 2015b). Esta evolución negativa traduce que la parte fundamental de los incrementos de productividad no se ha destinado a la elevación de los salarios y a la reducción de la jornada, sino al aumento de los beneficios empresariales. Supone una ruptura con la distribución que caracterizó en Europa a los llamados «treinta gloriosos» ${ }^{2}$.

En la UE 15, los incrementos salariales en términos reales que alcanzaban porcentajes del $5 \%$ en ese período, se redujeron al $3 \%$ en la década de los se-

${ }^{2}$ Este modelo de concertación y de reparto más equilibrado de la riqueza — como recompensa a la lucha de los trabajadores europeos en la II. ${ }^{a}$ Guerra Mundial en la recomposición de los dos imperialismos victoriosos de la época - no fueron ni «treinta» — sino 25- ni «gloriosos» (Arrizabalo, 2014: 314-315). Desde el auge del neoliberalismo, y más tras la caída de la URSS como contrapeso al capitalismo atlantista o fondomonetarista, las regresiones observadas en la distribución primaria equitativa de los excedentes económicos será igualmente relacionada para los casos español y gipuzkoano en Catrillón et al. (2016b; 2016c), siendo como veremos la fiscalización de estos beneficios empresariales y rentas de capital en general extremadamente baja, así como decreciente desde que se inició la crisis en 2008. Según Labeaga (2015) la reforma fiscal de 2015 ha reducido el impacto redistributivo del IRPF en España e implica una pérdida importante de recaudación. Según los escenarios simulados salen especialmente favorecidos quienes obtienen la mayor parte de su renta del ahorro (que se concentra más en las rentas más elevadas) y entre los más perjudicados destaca el colectivo de pensionistas. 
tenta del pasado siglo y al 1\% en la década de los ochenta, con diferencias entre periodos y que los muy altos salarios han concentrado una significativa porción de la parte salarial, lo que contribuye a oscurecer el declive de los salarios bajos y medios (Husson, 2010: 47 y ss.). En la última década no se ha alcanzado ese porcentaje e, incluso, en algunos países ha habido pérdida del poder adquisitivo de los salarios (Eurostat). Esta caída de la parte salarial, negada durante años, es aceptada en la actualidad por la generalidad de las instituciones internacionales.

En España, la reducción de la parte salarial va acompañada de un incremento de la desigualdad ${ }^{3}$. Como se acredita en el Gráfico 1, si comparamos los

\section{Gráfico 1}

Desiguales repartos de los ingresos por países en Europa: ratio 95\%/5\% en $2013^{4}$

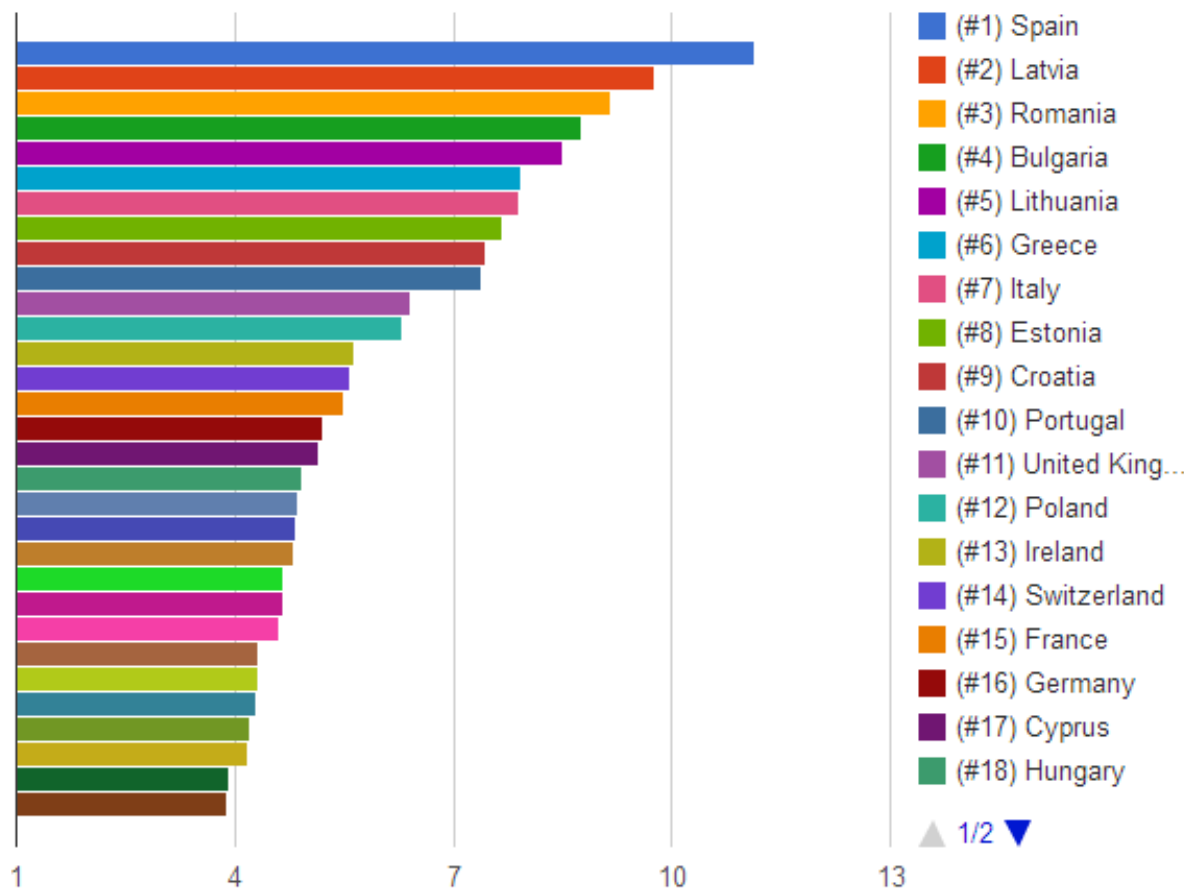

Fuente: Eurostat.

3 Lo mismo sucede en Euskalerria, con aumentos de la desigualdad en la repartición de la renta y una parte creciente de la misma en manos de una parte más pequeña de la población, siendo notable el cambio de 2009 a 2014 (ELA, 2015a).

${ }^{4}$ Ratio entre Percentil 95 / Percentil 5. El percentil 95 es la cuantía anual que gana la persona que en la base de datos observada está por encima del $95 \%$. El Percentil $5 \%$ es el sueldo anual de la persona que gana más que un $5 \%$ que tiene por debajo y menos que el $95 \%$ que le queda por encima. 
ingresos del hogar «que gana más que el 95\% de la población» en relación con el que «sólo gana más que un 5\%» tenemos el ratio 95\%/5\%. España ocupa, según Eurostat, el primer puesto en este indicador de desigualdad en Europa. De una cercanía con los otros países del sur de Europa - o GIPSI - que tienen un ratio 95\%/5\% en torno a 7, en España se ha un incremento muy notablemente hasta llegar, cómo vemos en el gráfico 1, a 11 en 2013.

Igualmente en Francia, la masa salarial evoluciona de 66\% del PIB en 1982 a $57,5 \%$ en 2007. Siendo el peso del consumo estable en torno al 58\% del PIB, esta caída en las rentas salariales tiene su contraparte en una aumento de la tasa de endeudamiento - respecto a la renta media anual disponible- del $65 \%$ en 1982 al 130\% en 2007 (Husson, 2012). Delaveau (2009) muestra que sólo de 1999 a 2007 el margen bruto de las sociedades no financieras del CAC 40 — principal índice bursátil francés- pasa del 40 al $48 \%$ y la parte de salarios en sus VAB del $60 \%$ al 51\%. Por último, Sapir (2009) nos recuerda que «la deflación salarial es un fenómeno indiscutible, pero que ha sido enmascarado por tres fenómenos» como son la introducción en los ingresos salariales de algunas rentas de capital, el incremento del peso de los «salarios» en el sector financiero - de $46 \%$ del VA sectorial en 1989 a 63\% en 2007-y el aumento de altas remuneraciones en algunos servicios como el gran comercio, la información y la comunicación, las actividades jurídicas o contables, la publicidad y, en general, el 1\% de las personas asalariadas — ver también Amar et al.— (2011: 38).

Esto datos dan cuenta de la vía actual de deflación salarial para sectores amplios de la población (Álvarez Peralta et al., 2012), así como del rol motor que juegan los GIPSI en esta estrategia en contra de la mayoría social trabajadora. La RTT es una medida eficaz para invertir este camino errático y repartir los aumentos de productividad entre sus principales artífices reconocidos, el conjunto de las personas trabajadoras.

Los adversarios de la RTT, en defecto de argumentos convincentes sobre su conveniencia para el bienestar de los trabajadores y de su justicia desde el punto de vista de un reparto equilibrado de los incrementos de productividad, se oponen a la RTT porque no sería eficaz para la creación de empleo. En este asunto hay que señalar que, además de la reducción de la jornada de trabajo en términos semanales, mensuales o anuales, también tiene efectos sobre el empleo la duración del trabajo a lo largo del ciclo vital. En este sentido, aunque no va a ser objeto de estudio en este trabajo, el aumento de la edad de jubilación preconizado insistentemente por la Unión Europea y puesto en práctica por la mayoría de los Estados miembros, al presionar hacia el mantenimiento en actividad de las personas trabajadoras mayores, va a contribuir a reducir el empleo de las más jóvenes.

A esta pauperización del trabajo en muchos frentes y, como hemos visto en De la Fuente y Zubiri (2016a), creciente dualización entre quienes se ven de 
forma sostenida excluidos de las relaciones laborales remuneradas y quienes, por contra, se ven avocados a realizar más horas o a la intensificación de sus tiempos de trabajo, hay que añadir la flexibilización creciente de la jornada en una mayoría de los sectores que emplean a buena parte de la población. Esta flexibilización es una pauta de organización empresarial en auge desde hace décadas ${ }^{5}$ y en constante adaptación tanto normativa como operativa. A diferencia de la RTT generalizada que supone la experiencia francesa de finales de la década de 1990 - que estudiaremos en este artículo-, la experiencia holandesa está, por contra, más centrada en el desarrollo del tiempo parcial (Jean, 2000; Visser, 2000), siendo esta modalidad contractual feminizada una pieza clave de las pautas actuales de flexibilización del trabajo.

Como ambas vías de RTT son simuladas en el plano puramente cuantitativo para su aplicación en Gipuzkoa (Castrillón et al, 2016d), en este artículo nos limitaremos a una exposición de los principales aspectos a tener en cuenta de la experiencia francesa. En esta materia, y más allá de la incidencia limitada que tuvieran las políticas de RTT que estudiamos a continuación, se puede observar en Francia una tendencia similar, en lo relativo a un incremento acumulado de la productividad desde hace décadas, en su mayor parte distribuido a los propietarios del capital y a una minoría de asalariados altamente remunerados.

\section{Precedentes normativos en materia de RTT en Francia}

La discusión teórica más detallada sobre la $\mathrm{RTT}^{6}$ y la experiencia práctica de cierta envergadura más reciente se han dado en Francia. Con anterioridad a estas leyes, el período comprendido desde el paso a las 39 horas en 1982, tras el acceso al gobierno de la coalición de "Unión de la Izquierda»", hasta la implantación a partir del 2000 de la semana de 35 horas, se caracterizó por un estancamiento en la duración de jornada de trabajo semanal. La reducción constatada se debió, según Husson (2007), a la progresión del tiempo parcial —en gran parte impuesto- en relación con el conjunto de los empleos ${ }^{8}$. El gobierno

\footnotetext{
5 Como bien modeliza Recio (1997) las implicaciones teóricas de la flexibilidad dependen de su acepción interna, externa o retributiva de la misma. Para una visión más aplicada, actual y comparada a nivel internacional ver Arriola y Vasapollo (2003).

${ }^{6}$ Para una síntesis del debate y balance de las experiencias, tanto francesas como internacionales, vease Cette y Taddei (1997).

7 Se estableció una quinta semana de vacaciones pagadas y un abono con el recargo del horario extraordinario para las horas trabajadas en exceso sobre las 39 horas.

${ }^{8}$ El tiempo parcial había tenido un escaso desarrollo en Francia hasta inicios de la década de los ochenta y su progresión fue paralela al aumento del desempleo. A fin de, por una parte, aceptar las demandas empresariales de aumento de la flexibilidad y, por otra, de maquillar el desempleo me-
} 
francés cambió de orientación económica a partir de 1982-83, tras la depreciación del franco y el aumento del déficit público y abandonó la perspectiva de las treinta y cinco horas semanales. Entre tanto en otros países europeos, tales como Alemania y Holanda, tenía lugar una significativa reducción de la jornada de trabajo a través de negociaciones colectivas estimuladas por los gobiernos (Bosh y Lehndorf, citados por Askenazy, 2014: 2).

En la década de los noventa, el desempleo masivo, en tasas superiores al $10 \%$, dio lugar a la vuelta de la idea de la reducción de jornada, especialmente impulsada por el sindicato CFDT, mientras que las organizaciones empresariales solo la aceptaban sobre la base de la voluntariedad - véase el detalle de las reacciones de las organizaciones empresariales y de la derecha política en De la Fuente- (2000: 44-45). En 1993, la llamada ley quinquenal «relativa al trabajo, el empleo y la formación profesional", asoció RTT — de al menos el 15\% del tiempo de trabajo-, creación de empleo y ayudas públicas — reducción del $40 \%$ de las cargas patronales los dos primeros años y $30 \%$ los dos siguientes-, lo que ha permanecido una constante en el derecho francés (Ray, 1998: 312). Su balance fue negativo ya que fue vista por la mayoría asalariada como una medida flexibilizadora sin contrapartidas para los asalariados.

En octubre de 1995 se firmó el Acuerdo Nacional Interprofesional (ANI) sobre el empleo cuyo objeto específico fue la duración y anualización del tiempo de trabajo. El ANI estableció el tiempo de trabajo como tema obligatorio de negociación, atribuyó un valor de cambio al tiempo de descanso y configuró al tiempo parcial como una elección de los asalariados... pero con compensaciones financieras para las empresas. Aunque el ANI fracasó desde el punto de vista del escaso número de acuerdos firmados, sirvió de base para las tentativas posteriores. En junio de 1996 la derecha conservadora aprobó la Ley Robien y pasó a estimularse la reducción voluntaria de la jornada trabajada entre el $10 \%$ y el $15 \%$, asociada a la creación de puestos de trabajo proporcionales a la reducción de la jornada. Para eso se utilizaron incentivos económicos consistentes en la reducción durante siete años de las cotizaciones empresariales.

diante el «reparto del empleo», los sucesivos gobiernos, tanto de derecha como de izquierda, estimularon el desarrollo del tiempo parcial, entre otras medidas mediante la reducción de las cotizaciones sociales a los nuevos empleos a tiempo parcial e, incluso, a la transformación de anteriores contratos a tiempo completo, así como a través de medidas de apoyo a los empleos de servicios a particulares, que se materializan muy mayoritariamente a través de este tipo de contratos (Daune-Richard, 2007: 258-9). Estos servicios a la persona son una punta de lanza de la precarización y creciente informalidad de unas relaciones salariales cada vez más feminizadas, siendo su auge y recomposición una confluencia de políticas económicas, sociales y familiares diversas y contradictorias (Jany-Catrice et Puissant, 2010 : 5-6) 


\section{Contenido de las Leyes Aubry (1998-2000)}

Tras la disolución del parlamento por el presidente Chirac en 1997, la coalición de izquierdas que se presentó a las elecciones convocadas incluyó, como elemento destacado del programa para contener la cifra récord del desempleo del $12,5 \%$, la instauración de las 35 horas a fin de cumplir el compromiso de $1981^{9}$. Normativamente se materializó por un paquete de dos leyes: la Ley 98 461, de 13 de junio de 1998, de Orientación y de Incitación relativa a la Reducción del Tiempo de Trabajo y la Ley de Reducción Negociada del Tiempo de Trabajo, de 19 de enero de 2000, conocidas como Leyes Aubry I y II. La segunda ley resultaba de una previsión del balance de aplicación de la primera, que como su mismo nombre indica tenía carácter incitativo, a través del estímulo a los acuerdos de empresa, de los que llegaron a firmarse hasta enero del 2000 en 23.275 empresas que comprendían a 2.700 .000 personas trabajando. El anuncio de las 35 horas encontró la oposición frontal de las organizaciones empresariales, con dimisión incluida del presidente del CNPF (MEDEF en la actuali$\left.\operatorname{dad}^{10}\right)$.

La Ley Relativa a la Reducción Negociada del Tiempo de Trabajo, de 15 de diciembre de 1999 (Ley Aubry II) ${ }^{11}$ establecía una jornada de 35 horas semanales a partir del 1-1-2000 para las empresas de 20 o más asalariados. A la exclusión de quienes trabajaban en empresas de menos trabajadores se unía la del sector no mercantil. De esta forma el número de potenciales beneficiarios, de 19,9 millones, se reducía a diez millones y daba lugar a que sólo 10 millones quedaban afectados por la ley, es decir, un $42 \%$ de los asalariados. Especialmente significativa era la exclusión de la ley de las empresas de menos de 20 trabajadores, ya que es justamente en este tipo de empresas en las que la duración del trabajo es más alta, sufren peores condiciones de trabajo y tienen un porcentaje más elevado de tiempo parcial. Además, daba lugar a procesos de fragmentación empresarial para evitar la aplicación de la ley. La ley contemplaba la posterior aplicación de las 35 horas, a partir del 1-1-2002, para las empresas que no alcanzasen el umbral de los 20 trabajadores. Inicialmente tampoco se aplicaba la ley a la función pública, estatal, local y hospitalaria (Euzeby, 2000).

9 Este mismo año de cambios políticos en Francia, el informe Rapport Chadelat proponía dos vías "como la puesta en práctica progresiva de una nueva base ampliada para la fiscalización del valor añadido o la modulación de tasas de cotización según el ratio masa salarial / valor añadido de las empresas contribuyentes» (Euzeby, 2000: 4).

10 El Conseil national du patronat français, posteriormente reconstituido en el Mouvement des entreprises de France (MEDEF), actual organización líder del gran capital empresarial en Francia.

11 Sobre esta ley y su precedente, entre otros, ver González Sánchez (1999: 89-140) y De la Fuente Lavín (2000: 33-65). 
La Ley Aubry II era una ley débilmente imperativa: las 35 horas son el punto de partida para los recargos legales de las horas suplementarias ${ }^{12}$, el descanso compensador y la modulación horaria. En la medida en que se admite la realización de un elevado número de horas suplementarias, de 130 horas anuales ${ }^{13}$ -que fue aumentado posteriormente-, la obligación de aplicar las 35 horas quedó relativizada, a pesar de lo cual fue calificada por la patronal CNPFMEDEF como una «ley autoritaria». La definición de las modalidades de la reducción de jornada se remite a la negociación colectiva y se requiere la realización de acuerdos de empresa o de establecimiento para el acceso a las ayudas de las empresas de más de 50 asalariados.

La duración media semanal no podía sobrepasar 44 horas semanales calculadas sobre 12 semanas consecutivas y la duración máxima era de 10 horas diarias y 48 semanales (por "circunstancias excepcionales" se pueden alcanzar las 60 horas). La Ley contemplaba y regulaba de nuevo la llamada «modulación» de la jornada, es decir, la posibilidad de anualización del horario a través de convenio colectivo de las empresas que pasasen a las 35 horas. Esos acuerdos de modulación pueden establecer duraciones semanales variables dentro del límite de 1.600 horas/año y de las duraciones máximas diarias y semanales, de forma que las horas realizadas por encima de las 35 semanales no tenían la consideración de horas suplementarias y, por lo tanto, no eran abonadas como tales. La Ley Aubry II contempla la posibilidad de individualización de la modulación, lo que fomenta la generalización de los horarios individualizados y, con ello, desaparecen las garantías derivadas de los horarios colectivos.

EL otro aspecto central para analizar esta experiencia de implementación de una RTT generalizada es el de las compensaciones salariales. Efectivamente, como explica Euzeby (2000), la Ley Aubry II estableció un aligeramiento del coste del trabajo de los salarios más bajos, tratando así de compensar en parte el aumento de los costes laborales unitarios (CLU) derivados de la RTT. Estos mecanismos se aplican de forma proporcional por tramos hasta las personas con remuneraciones menores a 1,8 veces el SMIC —Salario Minimo Interprofesional

12 El concepto y regulación de las horas suplementarias en Francia son diferentes de las horas suplementarias en los contratos a tiempo parcial en Espańa, mientras que son semejantes a los de las horas extraordinarias.

13 La ley preveía una remuneración diferenciada según que el asalariado estuviese o no empleado en una empresa que redujese la jornada a 35 horas o menos. En este caso, las cuatro primeras horas suplementarias tendrían un recargo del $25 \%$, bajo forma monetaria o de descanso. En las empresas que mantuviesen una jornada superior a las 35 horas, el recargo era del 15\%, al que se ańadía una contribución del $10 \%$ destinada a un fondo de las cotizaciones patronales a la seguridad social. Las horas suplementarias efectuadas por encima de las 39 horas daban lugar a un recargo del 25\%. La Ley Aubry fijaba que a partir de la hora 43 el recargo sería del 50\%. 
de Crecimiento $^{14}$-, siendo las rebajas en las cotizaciones sociales del $26 \%$ del salario bruto para los sueldos más bajos (menos de 1,2 veces el SMIC) y del 6,2\% para los que van de 1,6 a 1,8 veces el SMIC. En adelante se establece una cuota de reducción fija de 4.000 francos/mes de las cotizaciones sociales por asalariado (unos 650 euros del año 2000).

\section{Valoración crítica de sus efectos sobre la duración de las jornadas, el empleo y los salarios}

Además de incentivar y abaratar los bajos salarios, estas leyes favorecen la distribución irregular de la jornada y otras medidas flexibilizadoras, que resquebrajaron buena parte del apoyo inicial de la población trabajadora. Al no garantizarse el mantenimiento del salario y las condiciones de trabajo, la ley fue valorada por muchas personas asalariadas como un dispositivo para hacer lo mismo en menos horas, es decir empeorando las condiciones de trabajo (ritmos y horarios flexibles, trabajo en festivos) pero con menos salario y escasas perspectivas de creación significativa de empleo.

No obstante, el balance de la misma en términos de creación de empleo se mostró como más positivo que otras medidas de fomento del empleo basadas en la reducción del costo del trabajo: como resultado de una reducción de la jornada semanal media desde 38,9 a 36,9 horas entre los ańos 1997 y 2000, el balance del Ministerio del Empleo daba cuenta en febrero de 2001 que las 51.000 empresas que habían pasado a las 35 horas habían previsto crear unos 287.000 empleos.

Los resultados de los diversos modelos econométricos que se realizaron con motivo de las medidas legislativas de la Leyes Aubry preveían que la reducción de la jornada a 35 horas semanales supondría de 450.000 a 700.000 creaciones de empleo, efectos condicionados a la reducción parcial de salarios y reorganización del tiempo de trabajo ${ }^{15}$. En realidad, entre 1997 y 2001 se crearon dos millones de empleos en Francia, tantos como en el cuarto de siglo precedente y récord absoluto en el conjunto del siglo xx. Aunque es cierto que durante esos años tuvo lugar un importante crecimiento económico, el número de empleos creados sobrepasó ampliamente lo que se podía esperar de las fases anteriores de crecimiento (Husson, 2004: 2).

${ }_{14}$ Destacar como complemento el añadido en la denominación del SMIC francés respecto al SMI espańol, siendo esa última palabra la que asocia el aumento de los bajos salarios al crecimiento económico general de una economía. Peralta, Luengo y Uxó (2013) desarrollan esta centralidad del salario para un crecimiento mejor distribuido y de mayor tracción social en su diagnóstico sobre los países del Sur de Europa y las vías de salida a la crisis austericida.

15 Un breve resumen y bibliografía de los primeros años, en De la Fuente Lavín (2000: 42). 
El debate sobre el balance del dispositivo de las 35 horas se ha mantenido en el tiempo. Un informe de tres reputados economistas para el Conseil d'Analyse Economique (CAE) (Artus et al., 2007: 19), criticaba la normativa de las 35 horas por considerar que a su juicio habría acentuado el ritmo de disminución de la duración del trabajo en relación con los principales socios comerciales de Francia. Efectivamente, entre 1998 y 2004 la duración media anual del trabajo del conjunto de los asalariados habría disminuido el $1 \%$ en Francia, frente al 0,1\% en los Estados Unidos, el 0,2\% en España, el 0,4\% en el Reino Unido y el $0,9 \%$ en Alemania. Además, en Francia esa reducción se habría debido a una reducción de la duración de la jornada de trabajo de quienes trabajaban a tiempo completo mientras que en los otros países correspondería al desarrollo del trabajo a tiempo parcial. Según el informe, como la reducida jornada en Francia por habitante se debe en casi la mitad - 50\% - a la reducida jornada a tiempo completo, "la débil duración del trabajo de los asalariados a tiempo pleno contribuye de forma importante a las diferencias de ingreso entre nosotros y algunos de nuestros principales competidores» (Artus et al., 2007: 21). Este punto de vista obvia que la menor duración de la jornada de trabajo puede ser compensada por una mayor productividad (Askenazy, 2007).

En relación con la creación de empleo, los autores del mismo informe exponen que ningún estudio ha podido mostrar que una reducción de la jornada de trabajo dé lugar a la creación de empleos. Aunque apuntan que los estudios empíricos muestran que verosímilmente las Leyes Aubry han dado lugar a la creación de empleos — «en bastante gran número»—, agregan a continuación que ese efecto se ha debido a la reducción de las cotizaciones sociales sobre los bajos salarios y a la introducción de una flexibilidad incrementada en la organización del trabajo, concluyendo que, como mucho, la reducción de la jornada ha desempeñado un papel marginal sobre el empleo, «de signo indeterminado» (Artus et al., $2007: 58)$.

Sin embargo, como señalaba Husson (2004: 3), si como apuntaban los autores de este informe y otros economistas de orientación neoliberal, la reducción de la jornada derivada de las Leyes Aubry supuso una enorme elevación de los costes salariales, hubiera sido lógico — según sus propia teoría de la oferta vía reducción de costes - que las creaciones de empleo se hubieran producido con anterioridad a 1997 y no posteriormente, mientras que fue lo contrario lo que se produjo. Este autor recoge que, con diferencias, diversas instituciones han confirmado que la reducción de jornada creó un número significativo de empleos: 350000 según la Direction de l'animation de la recherche, des études et des statistiques (DARES), dependiente del Ministerio del Trabajo y el Empleo, 400000 según el Groupe Caisse des Dépôts (CDC), 500000 según el Institut de Recherches Economiques et Sociales (IRES), instituto de estudios al servicio de las organizaciones sindicales representativas. No existe, por tanto, explicación a las cifras de empleo alternativa a la RTT. Igualmente, Garzón (2015) muestra en el Grá- 
fico 2 este efecto positivo mediante las tasas interanuales de variación del empleo. De 1998 a 2000 — como hemos dicho, años de aprobación y aplicación de las Leyes Aubry I y II a las empresas de carácter mercantil de más de 20 personas asalariadas - se observan las variaciones de más incremento de empleo a lo largo de los últimos 50 años.

\section{Gráfico 2}

Evolución del empleo en Francia, 1956-2013.

Variación interanual del número de personas ocupadas

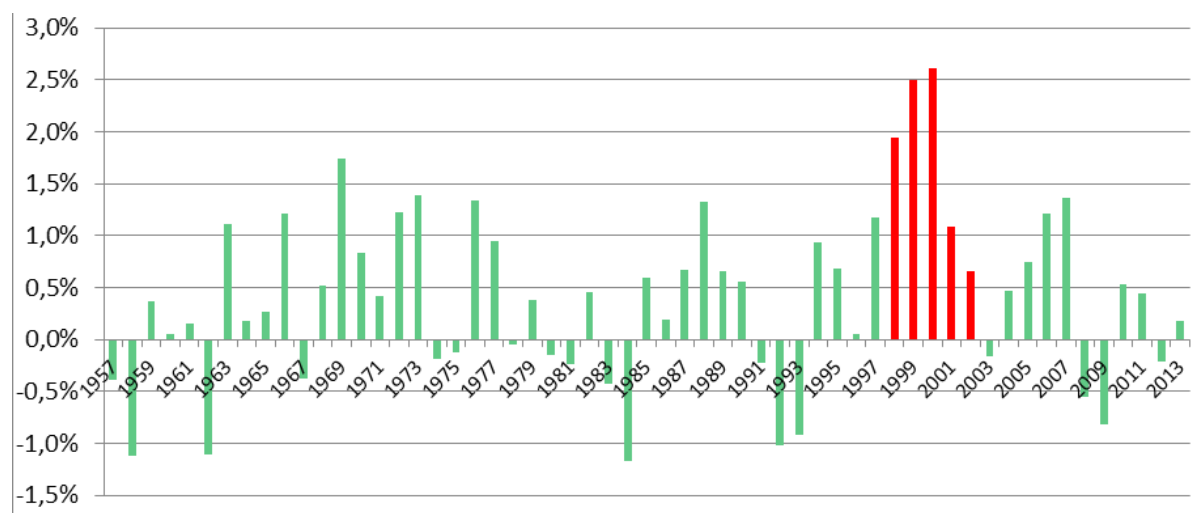

Nota: En rojo, los años de aplicación de medidas de reducción de jornada laboral.

Fuente: Garzón (2015) a partir de datos del Instituto Nacional de Estadística y Estudios Económicos de Francia. Equipo de Análisis Económico de la FEC.

Más allá de estas cuantificaciones sobre los efectos reales de las Leyes Aubry, la cuestión que se plantea es porque una reducción de la jornada de trabajo próxima al $10 \%$ (de 39 a 35 horas semanales), no dio lugar a un aumento proporcional de los empleos, ya que aplicada al conjunto de los efectivos, hubieran debido crearse 2,5 millones de empleos suplementarios, de los que 2,3 millones serían asalariados. Limitándose al sector mercantil no agrícola la cifra sería de 1,5 millones. Las razones de esa muy inferior creación de empleo son varias ${ }^{16}$.

16 En la experiencia de las $35 \mathrm{~h}$ en Francia se crearon entre $1 / 3$ y un $1 / 5$ de los empleos que resultarían de la asignación del total de horas liberadas a nuevos puestos de trabajo a tiempo completo. En Castrillón et al. (2016d) se constata que una aplicación generalizada de las 35 horas en Gipuzkoa liberaría una cantidad de horas como para crear 25.725 nuevos empleos a tiempo completo. Pendientes de estudio las diferencias exógenas — de situación macroeconómica—, endógenas — del tejido empresarial y social vasco- - y de diseño específico de las medidas en relación al caso francés de 1999-2001, se puede constatar que esta horquilla 1/3-1/5 supondría en Gipuzkoa la creación de 6.400 a 8.600 nuevos empleos a tiempo completo. 
Por una parte, por la citada inaplicación de las 35 horas a las pequeñas empresas, muy numerosas en el tejido productivo francés de la época ${ }^{17}$. Por otra parte, por las posibilidades, también mencionadas, de anualización de la jornada y, en general, de flexibilización horaria y de intensificación del trabajo.

La misma Ley Aubry I ya contemplaba de antemano implícitamente ese efecto cuando fijaba, como condición para la percepción de ayudas, una creación de empleo del $6 \%$ para reducciones de jornada del 10\%. Tal estimación preveía, pues, que la RTT irá acompañada de una importante intensificación del trabajo, que efectivamente tuvo lugar y que explica las reticencias de los asalariados respecto a la Ley. La Ley Aubry II profundizó la debilidad en este sentido de la primera, no exigiendo ninguna creación de empleo a las empresas para beneficiarse de la reducción de las cotizaciones sociales.

La comisión parlamentaria de encuesta que hizo público sus resultados - conocidos como Rapport Romagnan (2014), por el nombre su informadoraen diciembre de 2014, da por buena la cifra de 350.000 empleos como producto de la introducción de las 35 horas por las Leyes Aubry. Su coste anual fue de dos mil millones de euros para las empresas y 2,5 mil millones para las administraciones públicas, es decir, 12.800 euros por cada empleo creado, 5.750 a cargo de la empresa y 7.150 de la administración. A comparar esta última cuantía con los 12.744 a que ascendía en el 2011 el gasto por indemnización media de un desempleado. Así como que las ganancias y la competitividad de las empresas no se vieron resentidas, este informe recuerda también que la aplicación fue irregular y en cierta parte vía más días libres. Aún así, estima en muy positiva su incidencia sobre el descenso del n. ${ }^{\circ}$ de parados de 1999 a 2001 - de los 350.000 empleos mencionados hasta 600.000 inscritos menos en el SPE francés- en la época ANPE, hoy Pôle Emploi — durante el mismo periodo-. El informe concluye que «es la politica a favor del empleo más eficaz y menos costosa que ha sido conducida desde los años 1970» (Romagnan, 2014). Este informe ha sido objeto de apreciaciones diversas en función de la proximidad o no a la jor-

17 Enero de 2002 era la fecha prevista para la aplicación de las 35 horas a las pequeñas empresas. Sin embargo, un Decreto de 15-10-2001, elevó de 130 a 180 el número de horas suplementarias que puede realizar anualmente cada asalariado en las empresas de menos de 20 trabajadores, lo que permitía a las empresas mantener la jornada de 39 horas con un coste reducido. Además, solo las horas realizadas por encima de la 37. ${ }^{\mathrm{a}}$ eran computables para ese contingente de 180 horas. Sólo en caso de sobrepasar las 180 horas anuales, computadas como se ha indicado, el empresario tendría que solicitar autorización a la inspección de trabajo y, en su caso, abonarlas con un recargo superior. Según la DARES (2003) sólo el 16\% de las empresas de menos de 20 asalariados tenían una jornada de 35 horas semanales a finales de 2002. De las mismas un 50\% había reducido la jornada antes del plazo legal. Euzeby (2000) destaca, entre otros problemas, las dificultades de reorganización más acuciantes en las PyMEs de cara a una política de RTT. También apunta la importancia de buscar vías de financiación que compensen el gasto de estas medidas para la recaudación pública, siendo la fiscalización de los beneficios de las grandes empresas — con aplicación de RTT más fácil de organizary la disminución de sus ventajas contributivas la vía a su entender más acertada. 
nada de las 35 horas, desde quienes lo han saludado como la «rehabilitación de las 35 horas" (Liberation, 11-12-2014) hasta quienes han dicho que "repinta en rosa» las 35 horas (Le Figaro,17-12-2014).

Varios de los economistas que elaboraron el informe citado para el Conseil d'Analyse Économique de 2007, han manifestado en una tribuna periodística del año 2014 (Cahuc et al., 2014), que «la reducción del tiempo de trabajo no tiene ningún efecto positivo sobre el empleo». Para llegar a esa inclusión indican que la implantación de las 35 horas fue acompañada de la reducción del coste del trabajo a través de la bonificación de las cotizaciones sociales, por lo que para evaluar ese impacto sería necesario comparar un grupo test que se beneficia y un grupo testigo que no lo hace. Sin embargo, como señala Husson (2015) los estudios antes citados que han conducido a un consenso sobre los $350.000 \mathrm{em}$ pleos que habrían resultado de las 35 horas compararon las empresas que pasaron a las 35 horas y las demás, por lo que la objeción sería absurda en la medida en que el paso a las 35 horas se realizó a través de un proceso de negociaciones que combinaba de forma indisociable la reducción del tiempo de trabajo, las bonificaciones de las cotizaciones sociales y el aumento de la productividad resultante de la reorganización del trabajo ${ }^{18}$.

En relación con sus efectos sociales se ha subrayado que son los obreros y las mujeres quienes han perdido en el paso a las 35 horas (Husson, 2004: 3). Los obreros por la pérdida de salario: aunque el salario base se mantuvo en términos generales, la anualización de la jornada trajo consigo la supresión de un gran número de horas suplementarias, cuyo importe ha constituido históricamente una parte muy importante del salario en Francia. Ello afectaba a numerosas grandes empresas que se enfrentan a pedidos fluctuantes y también una parte importante del comercio. Los asalariados cuyo salario era del nivel del SMIC y que trabajaban en empresas que permanecieron trabajando 39 horas se beneficiaron plenamente de los aumentos del salario mínimo horario acordados a partir de 2002 para asegurar simplemente el mantenimiento del poder de compra mensual de los asalariados pasados a las 35 horas. Los cuadros salieron "ganadores» por los dispositivos de las compensaciones en días de reposo del horario suplementario (Askenazy, 2008), aunque cada vez más el mayor tiempo libre es puramente teórico por el trabajo que se realiza desde el hogar, favorecido por las nuevas tecnologías y su capacidad de expansión de las tareas productivas al conjunto de esferas de la vida social e íntima (Morini, 2014: 72).

Para las mujeres no se produjo una reabsorción de los empleos a tiempo parcial no escogido, perdiéndose la ocasión de aproximar la situación en relación

18 Para una aproximación técnica a estas cuestiones sobre las tipologías de interrelación entre RTT, reorganización del trabajo, productividad, compensaciones salariales y creación de empleo ver Alonso y Pérez (1996). 
con sus aspiraciones: de media trabajaban 23 horas semanales en el año 2004, mientras que deseaban trabajar 32. De esta forma se consolidaba el mantenimiento de las desigualdades entre mujeres y hombres que, en Francia como en otros países, están asociadas al tiempo parcial, que se expresan por una concentración de las mujeres entre los empleos escasamente remunerados (el 80\%) y la polarización entre un segmento de mujeres altamente calificadas que, cuando trabajan a tiempo parcial lo hacen con jornadas de 30 o más horas y, por otro lado las mujeres de menor calificación que oscilan entre el desempleo y los trabajos precarios y que cuando trabajan a tiempo parcial lo hacen con jornadas de menor duración, frecuentemente temporales y con horarios muy desfavorables para la vida familiar (Galtier citado en Daune-Richard, 2007: 259).

El citado informe de la Commission d'enquête de l'Assamblée Nationale (Romagnan, 2014) ratifica los grupos sociales perdedores de la aplicación flexibilizadora de las 35 horas: los asalariados con menor formación han sufrido el incremento de la polivalencia así como de una menor previsibilidad de los horarios de trabajo. Entre ellos, el $40 \%$ de las mujeres no calificadas que no habrían obtenido «ningún beneficio» de la reducción del tiempo de trabajo.

Teniendo en cuenta que la «conciliación» —o conflicto irresoluble (Orozco, 2014) — entre el trabajo para los mercados capitalistas y el de cuidado familiar y en la vida comunitaria no debe afectar solo a las mujeres, las modalidades de aplicación del paso a las 35 horas mostraron la hipocresía de ese discurso sexista tan al uso ${ }^{19}$. En efecto, las direcciones de las empresas utilizaron a fondo las posibilidades de flexibilización incrementada permitidas por las Leyes Aubry, aumentando las contradicciones entre tiempo de trabajo y tiempos sociales, en el sentido de que la modulación de la jornada, además de hacer a los ritmos de trabajo más irregulares e imprevisibles, favorece los momentos de la jornada en los que las mujeres (teniendo en cuenta la división de tareas domésticas existentes) tienen más necesidad de tiempo libre (Husson, 2004: 4).

Esa política mantiene y refuerza la tendencia histórica del modelo francés de priorización del papel de las mujeres en el espacio privado y de consideración

19 Discurso sobre la "conciliación» principalmente orientado más allá de la galería a las mujeres y que plantea cuestiones de fondo sobre el reparto social y colectivo de los por todos y todas necesitados cuidados, así como las embestidas, desequilibrios y desigual reparto estructural y permanente en la provisión de cuidados por todos y todas necesarios. A nuestro entender, este discurso viene a decir: "Mujeres a conciliar!, haceros a un lado "con derechos", reduciros las jornadas o no os preocupéis si os imponen jornadas más cortas, flexibles, intermitentes y/o intensas, o el paro y la pérdida de aptitudes profesionales específicas de oficio. Eso todo os ha tocado pero mirarlo por el lado bueno, os dará más tiempo para cuidar». Un aumento de este imaginario genera problemas reaccionarios de toda índole, sobre todo cuándo los sistemas contributivos y de protección siguen mayormente anclados en un modelo laboral de empleo ininterrumpido y a tiempo completo, cada vez menos generalizado en las nuevas generaciones de hombres $\mathrm{y}$, sobre todo, mujeres adultas. 
del empleo de las mujeres como un peligro para su salud, fecundidad y capacidad para educar a hijos y cuidar personas con necesidades especiales de atención, mayormente ancianas. Este modelo se ha manifestado en una legislación "protectora» de la madre trabajadora desde finales del siglo XIX —limitación de la jornada de trabajo y prohibición del trabajo nocturno (que no se eliminó hasta el 2001) (Daune-Richard, 2007: 248-9) — lo que ha "permitido" una incorporación masiva de las mujeres a los sectores de empleo centrales en la recomposición de las economías salariales de servicios (Albarracín, 2003; Zubiri, 2014) ${ }^{20}$.

\section{Evoluciones posteriores, regresión en las políticas de RTT}

La legislación posterior ha vaciado de sustancia a las Leyes Aubry. La ley de 21 de agosto de 2007 A favor del Trabajo, del Empleo y del Poder de Compra (Ley $T E P A)$ fue aprobada a instancia del nuevo gobierno de la derecha francesa, presidido por Nicolas Sarkozy. Esta ley, que según la ministra de empleo estaba "consagrada a la confianza, el crecimiento y el empleo", y sería la primera etapa de una "carrera para hacer ingresar nuestro país en el siglo XXI». La "desfiscalización» de las horas suplementarias, es decir, la exoneración del importe de las horas suplementarias en el impuesto de la renta y la reducción de las cotizaciones sociales a los empleadores que recurriesen a las horas suplementarias, era uno de los ejes de la ley TEPA y fue calificada por la entonces Ministra de la Economía y el Empleo Mme. Lagarde (hoy directora del Fondo Monetario Internacional y miembro destacado de la Troika) como «medida faro de la ley» y que encarnaba la declaración en la campaña electoral, en abril de ese mismo año, de Nicolas Sarkozy de travailler plus pour gagner plus ${ }^{21}$ ya que, a su entender, constituía el «único medio creible de aumentar los salarios de los obreros.

La desfiscalización de las horas suplementarias fue la alternativa del gobierno Sarkozy a la derogación formal de la Ley Aubry sobre las 35 horas. Para ello se incitaba a las empresas a recurrir a las horas suplementarias, mediante la exención a las mismas de las cotizaciones sociales. Estas suponían un importante

20 Esta especialización sectorial del empleo femenino es, en el caso de Francia: el comercio, la salud-acción social-educación; los servicios mercantiles auxiliares y en general tareas administrativas o de cuidado; $y$, por último en importancia, todo lo relacionado con la economía del conocimiento (Foray, 2009; Rodríguez et Esteban, 2009).

21 "Trabajar más para ganar más» que se opone frontalmente, empezando por el campo semántico, al Lavorare meno per lavorare tutti que preconizábamos en De la Fuente y Zubiri (2016a). Para un análisis detallado de ese ciclo de movilizaciones, huelgas y acciones sindicales desde sectores precarios ver Zubiri (2011) y, para luchas más específicas en sectoores precarizados, Béroud et Bouffartigue (2009). 
coste para el Estado y una mínima ganancia para una parte de los asalariados ${ }^{22}$, a costa del conjunto de contribuyentes. Además, esa medida podía tener un efecto contraproducente, en la medida que orientaba a las empresas a optar por el recurso a las horas suplementarias en lugar de proceder a nuevas contrataciones.

El citado informe para el Conseil d'Analyse Économique (Cahuc et al., 2014), que recordamos era muy hostil a la implantación de las 35 horas, señalaba que:

Una disminución de la tasa de recargo de las horas suplementarias entraña un aumento de la demanda de horas suplementarias por las empresas y una substitución de las horas de trabajo en los puestos de trabajo desfavorable al empleo y el ingreso global».

De acuerdo con su tesis — según la cual la disminución de coste del trabajo favorece el empleo-, consideraban que esos factores se contrarrestaban, por lo que concluían que su efecto fue "ambiguo» e «incierto" y, además, favorecería los comportamientos "oportunistas", tales como el consistente en los acuerdos conjuntos, que podrían suscribir empleadores y asalariados de reducir (o no aumentar) el salario de las horas normales y declarar ficticiamente horas suplementarias y beneficiarse así fiscalmente (Artus et al., 2007: 11). La desfiscalización de las horas suplementarias a efectos del impuesto sobre la renta y la exención de las cotizaciones sociales fueron suprimidas en agosto y septiembre de 2012 respectivamente, pero se mantiene la citada exención para las empresas de menos de 20 trabajadores.

La ley de 20 de agosto de 2008 con el ponposo nombre de Rénovation de la démocratie sociale et réforme du temps de travail ${ }^{23}$ permite a los asalariados trabajar hasta 40 horas semanales (y, en algunas condiciones, hasta 48). Las horas suplementarias se "desencadenan" desde las 35 horas, pero el límite anual está fijado en la enorme cifra de 220 horas/año y el número de días durante las que se pueden realizar se aumenta desde 218 a 282 días. Hasta entonces reservado a los cuadros, el nuevo límite se extiende a todos los asalariados que sean autónomos en su trabajo. Se permite reemplazar el abono en metálico de las horas suple-

22 Las primeras horas extras de 35 a 39 semanales pasaron, en algunos supuestos, a cotizar al $10 \%$ suplementario, frente al $25 \%$ que se había establecido previamente.

23 Más allá de la cuestión de la RTT, Barbier (2009) considera que son cuatro las principales reformas sociolaborales regresivas en este periodo de inicio del mandato de Sarkozy:

— El acuerdo del 11 de enero del 2008 «de modernización del mercado de trabajo» —firmado entre la patronal, el Gobierno y 4 de los 5 sindicatos «representativos»— (salvo la CGT).

— La ley del 1 de agosto sobre «los derechos y deberes de los demandantes de empleo».

— La desintegración y fusión de dispositivos en la creación de un sólo SPE, llamado Pole Emploi.

- Y la reforma de la Renta Mínima de Inserción y su activación en el Revenue de Solidarité Active — Renta de Solidaridad Activa — analizada en Zubiri (2009). 
mentarias mediante acuerdo de empresa o de establecimiento o, en su ausencia, mediante convenio o acuerdo de rama, por reposo compensador equivalente. En este caso las horas suplementarias no son imputables para el límite anual establecido.

De esta forma esta ley consagra la fungibilidad entre tiempo y dinero, favorece una máxima flexibilidad en la organización de los tiempos de trabajo a un nivel muy descentralizado y a los acuerdos individuales. Al dejar en segundo plano los acuerdos de rama salta un instrumento protector de los asalariados. Si las Leyes Aubry habían establecido un lazo entre tiempo de trabajo y empleo — débil, tal y como se ha seńalado — pero no forzaba al mantenimiento del poder adquisitivo de los salarios. La nueva normativa iniciada con esta ley de 2008 privilegia, por contra, la relación de los tiempos y el poder de compra (aunque de ninguna forma garantiza su incremento), obviando el aspecto del empleo (Baron, 2008).

Lejos de suponer un cambio de tendencia a favor de la RTT, la llegada de Hollande a Presidente de la Republica implica, entre otras medidas, la Ley 2013-504 de Securisation de l'emploi de 14 de junio de 2013. Esta ley permite a las partes sociales, mediante acuerdos mayoritarios con el compromiso de los empleadores de no proceder a despidos por causa económica mientras dure el acuerdo, además de otras medidas, que se puedan derogar las Leyes Aubry. Mediante acuerdos de mantenimiento del empleo las empresas pueden incrementar el tiempo de trabajo sin compensación salarial o, incluso, reducirlo con reducción del salario. Hasta el 15 de marzo de 2015 se habían suscrito diez acuerdos de mantenimiento del empleo, que en general afectan a pequeñas y medianas empresas y con la duración máxima prevista en la ley de dos años. En materia de tiempo de trabajo las medidas consisten en aumento de la duración semanal del trabajo (desde 50 minutos a 3h15) y/o al número de días trabajados hasta cinco días, todas ellas sin compensación salarial.

Las direcciones de las empresas optan, en muchos casos, por no cuestionar el dispositivo de las 35 horas que les ha permitido anualizar y flexibilizar el tiempo de trabajo, especialmente en sectores como la gran distribución comercial que, mediante una anualización acomodada a los picos de actividad, permite a las empresas ahorrar en el pago de horas suplementarias. A pesar de la posición "pragmática» de algunos sectores, por la dirección de las organizaciones empresariales y por dirigentes políticos, no solo de la derecha sino también de una cierta izquierda — como el primer ministro Manuel Valls_, se mantiene la carga ideológica contra las 35 horas (Foulon, 2014). Así, Denis Kessler, PDG del grupo de reaseguro SCOR y antiguo vicepresidente del MEDEF publicaba un artículo en Le Monde en octubre de 2012 con el muy revelador título Il est temps d'abolir les 35 heures [Es tiempo de abolir las 35 horas] (Kessler, 2012). En ese artículo su autor se declara escandalizado porque las medidas de 
armonización de los diferentes mínimos salariales establecidas por un gobierno de la derecha (Raffarin) consecuencia de la Ley Aubry II habrían conducido a un aumento del SMIC hora del 31\% entre 1998 y 2005, produciendo un desenganche industrial y comercial de Francia durante ese período. Asimismo criticaba el aumento de efectivos de la función pública debido a la aplicación a la misma, no contemplada inicialmente, de las 35 horas, a la que contrapone la «virtud» del ejemplo alemán de establecer en 41 horas semanales la jornada de los funcionarios federales y exponía, que frente a la ilusión de que Francia fuese el motor de una extensión de las 35 horas a toda Europa, Francia se había quedado aislada.

Aunque formalmente se mantiene la referencia legal de las 35 horas semanales de jornada las empresas pueden pedir a los asalariados trabajar más horas (o más días). Esta política está facilitada por un coste de una hora suplementaria que es apenas superior al de una hora normal, lo que contrasta con otras regulaciones, como por ejemplo la de Estados Unidos donde las horas realizadas por encima de las 40 horas semanales se abonan con un recargo del $50 \%$ y las modulaciones-anualizaciones de jornada no son, en general, posibles. De esta forma se ha afirmado que el modelo francés es más próximo en la actualidad al del Reino Unido, donde predomina la individualización de las jornadas de trabajo. En este aspecto la regulación de los Estados Unidos sobre la compensación de las horas extraordinarias es un ejemplo de buena práctica.

La última referencia legislativa al tiempo de trabajo se contiene en la reforma laboral contenida en la llamada Ley El Khomri (por el nombre de la Ministra de Trabajo), cuyo proyecto de Loi Travail ha sido aprobado por el Consejo de Ministros el 24 de marzo de 2015, en medio de importantes movilizaciones laborales y estudiantiles. En el proyecto queda en suspenso la fijación de la duración legal que desencadena el pago de las horas suplementarias con recargo, ya que el Informe Badinter (2016) en el que se ha inspirado la ley estipula en su art. 33 que:

La duración normal del trabajo es fijada por la ley. Esta determina las condiciones en las que los convenios y acuerdos colectivos pueden establecer una jornada diferente. Todo asalariado cuyo tiempo de trabajo sobrepase la duración norma tiene derecho a una compensación.

Sin embargo, como señala Harribey (2016) este artículo coexiste con el art. 1 que establece como valor esencial el buen funcionamiento de la empresa, lo que deja en la duda si prevalecerá la duración con compensación legal o la «libertad» de la empresa de hacer lo que quiera.

El proyecto refuerza la flexibilización del tiempo de trabajo diario y semanal, facilitando la modificación unilateral de los horarios por parte de la dirección de 
las empresas ${ }^{24}$. Facilita que los empleadores puedan imponer en el tiempo parcial una jornada más reducida que la mínima general, de 24 horas semanales. El Consejo Superior de la Igualdad Profesional en un informe hecho público el 113-2016 ha señalado que estas medidas flexibilizadoras del tiempo de trabajo van a penalizar a las mujeres (Gasté, 2016). Asimismo reduce para nuevos casos del $25 \%$ al $10 \%$ el recargo de las horas suplementarias ${ }^{25}$. Las nuevas posibilidades contempladas para los «acuerdos de competitividad» permiten a los empresarios imponer las modulaciones de jornada, de los salarios y de la movilidad, que en caso de no aceptación por las personas asalariadas pueden suponer el despido de las mismas.

Esta ley ««socialista»» (Béroud, 2016), en proceso de discusión en el momento de entregar este artículo, requiere aún de un impulso final por parte de un gobierno que se enfrenta — en Estado de excepción, decretado tras los atentados de París en noviembre del 2015 - a una base social y sindical muy movilizada desde finales de febrero. Desde la petición espontánea con más de 1,3 millones de firmas y las primeras y fuertemente reprimidas movilizaciones juveniles y estudiantiles, ya se ha pasado al siguiente nivel, con dos grandes jornadas de huelga general inter-profesional el 31 de marzo y el 28 de abril, universidades y liceos con bloqueos constantes y múltiples días de acción social y sindical unitaria, además del movimiento de ocupación nocturna de las plazas "Nuit Débout», que ya alcanza ciudades grandes y pequeńas de todo del país ${ }^{26}$.

${ }^{24} \mathrm{El}$ art. 3 del proyecto de ley prevé que se puede derogar el límite ordinario de la jornada de trabajo de 10 horas diarias, pasando a 12 horas, que en caso de desacuerdo entre la dirección de la empresa y la representación de los trabajadores, se puede realizar mediante acuerdo de «la autoridad administrativa» (hasta ahora se requería que se acuerdo se dictase por la inspección de trabajo). El mismo art. 3 contempla que la jornada semanal puede alcanzar las 44 horas durante un período máximo de 16 semanas (antes 12). Mediante acuerdo de empresa o sector la duración puede llegar a 46 horas semanales. Se mantiene la posibilidad de 60 horas semanales en caso de "circunstancias excepcionales».

${ }^{25}$ Hasta ahora el recargo del $25 \%$ se aplica a las primeras ocho horas, siendo del $50 \%$ a continuación, si bien puede reducrise al 10\% si así lo establece un acuerdo de empresa o de sector. El nuevo anteproyecto establece que el acuerdo de sector, generalmente más ventajoso, solo se aplica si no existe acuerdo de empresa, lo que permite temer que se produzca una nivelación hacia bajo del recargo, del 10\%, bajo presión de los empleadores. Además el proyecto amplia de 1 a 3 años el período en el que las horas suplementarias pueden ser computadas (mediante pago o en tiempo) en caso de que de acuerdo colectivo y de una a 16 semanas en caso de «decisión unilateral».

${ }^{26}$ http://loitravail.lol/ ; http://www.nuitdebout.fr/ ; http://www.solidaires.org/ —por ejemplo, Solidaires (2016)—; https://lundi.am/ 


\section{Balance de la experiencia francesa: Aprendizajes para los tiempos presentes}

Si el crecimiento económico era insuficiente para erradicar el desempleo en Francia en la década de los noventa y a inicios del 2000, lo es mucho menos en la actualidad. Como recoge el informe de la Comission d'enquête de l'Assamblée Nationale (Romagnan, 2014), para que el crecimiento del PIB redujera sensiblemente el desempleo haría falta que se estableciera en unos niveles muy superiores a los de las últimas décadas, lo que, señala el informe, parece fuera de toda perspectiva razonable, entre otros factores por el nivel elevado de endeudamiento (Lordon, 2008; Husson, 2012) y por la rarefacción de los recursos naturales sobre los que se ha apoyado el crecimiento económico en el siglo xx (Fernández Durán et al., 2015).

En el actual contexto, la reducción del tiempo de trabajo es el mejor instrumento para combatir el desempleo, tal como lo ha mostrado la experiencia de las Leyes Aubry. A pesar de que la flexibilización del tiempo de trabajo promovida por esas leyes contribuyó a minorar su impacto en la creación de empleo, los resultados obtenidos fueron muy superiores a los resultantes de la política de reducción del coste del trabajo a través de las bonificaciones a las cotizaciones sociales. Más allá de la cuestión de la RTT, la vía de exoneraciones en las cotizaciones sociales ha sido la tónica general de la política de empleo en Francia desde hace décadas hasta hoy. Además de su implicación en el recorte de los salarios indirectos y diferidos, su alto coste y eficacia en la creación de empleo ha sido puesta en cuestión por L'Horty en Carbonier et al. (2015), al hilo de un estudio más detallado de los costes y efectos de estas políticas en Francia desde la década de 1990 (Carbonier et al., 2014). Koléda (2015) también ha contribuido recientemente a este debate, apoyando una exoneración de los salarios medios, en vez de los más bajos, lo que puede poner fin con la «subvención a la precariedad» que implica la incentivación pública de los bajos salarios.

Volviendo a la cuestión que nos ocupa, para que la RTT contribuya, además de a la creación de empleo, a la mejora de las condiciones de trabajo de la gran mayoría asalariada, debe evitar algunas de las medidas de las Leyes Aubry tales como la supresión de los tiempos de pausa y, en general, las medidas de flexibilización extrema impuestas por la dirección de las empresas, que han perjudicado de forma especial a las mujeres. A pesar de estas medidas, Husson (2016) muestra que en Francia tuvo lugar una reducción considerable de la «duración efectiva de trabajo» entre 1998 y 2002. Esta tendencia se estanca a partir de este momento con subidas y bajadas anuales más moderadas, lo que explica la subida del paro.

La RTT puede contribuir a la igualdad profesional entre mujeres y hombres en la medida en que permita a los padres-hombres dedicar más tiempo a las 
tareas domésticas y de cuidado, lo que se ha realizado pero a medias en el caso francés. Como señala el informe de la Commision d'ênquete (Romagnan, 2014) la mayor inversión en esas tareas por los hombres es un paso obligado para la igualdad profesional entre los sexos, ya que la mayor ventaja competitiva de los hombres se basa justamente en su menor dedicación a las tareas domésticas y el sacrificio correlativo por las mujeres de su vida profesional para ocuparse de esas tareas (Carrasco et al., 2011).

Por último, recordar que se mantiene en tasas muy elevadas el tiempo parcial realizado por las mujeres (ocupan el 82\% de esos trabajos). La duración más amplia del tiempo parcial en Francia en comparación con otros países europeos (23,2 horas semanales de media en Francia en el 2010 según Eurostat frente a 20,2 horas en la UE) no asegura, sin embargo, mayoritariamente la autonomía financiera de las mujeres que realizan el trabajo bajo esa modalidad. En este sentido la RTT generalizada constituye un mecanismo más democrático y equitativo de reparto del trabajo existente. Husson (2016) considera que, con una reducción generalizada del tiempo de trabajo de en torno al $10 \%$, se podría erradicar el paro, llegando a las "35 horas efectivas", a partir de las 39 horas de media que se siguen hoy realizando en Francia. Esto "puede ser perfectamente compensado por una bajada de los dividendos distribuidos a los accionistas» (7).

\section{Conclusiones}

En este artículo hemos realizado una revisión sistemática de los principales aprendizajes de la experiencia francesa de RTT, con especial atención a su efecto sobre el empleo durante los años de implementación de las Leyes Aubry de 1998 y 2000. Hemos empezado dando cuenta de los retrocesos en la equidad distributiva de los excedentes y las rentas en las economías europeas. Con especial atención a los casos español, vasco y francés, hemos comprobado que en los tres casos la parte de los salarios en el PIB retrocede en las últimas décadas, pasando en los dos primeros casos por debajo de la barrera simbólica del 50\% del PIB desde 2012.

Además, hemos constatado que España ocupaba el primer puesto en la desigual distribución entre rentas más altas y las más bajas el año 2013, con un aumento muy notable de este ratio desde el 2008, año dónde se encontraba más cerca en equidad respecto al resto de países del Sur de Europa - los GIPSIEn el caso francés hemos podido comprobar que algunos efectos estadísticos de inclusión de salarios altos, del sector financiero o en otros servicios de alto valor añadido, hacen subestimar la evolución de las desigualdades en el reparto de rentas. Todo lo expuesto permite concluir que «los incrementos de productividad no se ha destinado a la elevación de los salarios y a la reducción de la jornada, sino 
al aumento de los beneficios empresariales» (De la Fuente y Zubiri, 2016a; Castrillón et al., 2016b; 2016c).

Dando paso a nuestro objeto principal, el análisis de las Leyes en el caso de Francia, ha sido realizado en su contexto histórico mediante sus antecedentes, que son políticas tímidas de RTT en unas claves principalmente flexibilizadoras y con vocaciones de desfiscalizar más los bajos salarios que de hacer una política de RTT generalizada a favor de las personas trabajadoras. El giro importante se produce con las Leyes Aubry en 1998 y 2000, con una aplicación progresiva de las 35 horas con vocación de llegar en dos años al conjunto de la población asalariada.

Hemos podido comprobar que rápidamente se reduce a la mitad los potenciales beneficiarios de la RTT planteada como supuesto marco general. Aún así, su implementación entre 1999 y 2001 generó unas evoluciones muy positivas en el empleo y grados de aplicación flexible y variables. En cualquier caso, esta reforma logra implementar la normalización en muchos sectores de las 35 horas, o al menos el aumento de su incidencia durante los ańos posteriores. En esa época se dan en Francia caídas globales de la jornada anual media más relevantes que en Alemania y mucho más que en España, Gran Bretańa o EE.UU.

Además de los 400.000 a 700.000 empleos que se crearon, los efectos sobre reducciones parciales de salarios - vía exenciones de cotizaciones - y la reorganización de los tiempos de trabajo fueron significativas. Por último, cabe destacar que los aumentos en los costes laborales globales inmediatamente posteriores a la implementación de la Ley no tuvieron un efecto negativo sobre el empleo, sino más bien todo lo contrario.

Hemos podido ver también que un reciente informe de la Assemblée Nationale (Romagnan, 2014) realiza una evaluación de los costes netos entre 1999 y 2001 y que cada puesto creado no tuvo un coste — para empresas y entidades estatales - muy alto y a la par de la barrera simbólica del coste medio anual por desempleado. En otros trabajos de mayor componente crítico (Husson, 2004; 2012), hemos podido mesurar el impacto a la baja sobre los salarios, si no de forma sistemática si de facto para muchos casos. Así mismo se constata el error de sus aplicaciones analizadas — con medidas flexibilizadoras que impiden una transformación de la organización social y reparto de los trabajos diarios de cuidados- y la ventaja relativa de los trabajadores de empresas que prefirieron seguir en 39 horas semanales pasando por un coste fiscal en beneficio del asalariado.

Además de tratar otras cuestiones sobre estas leyes, hemos podido ver en el desarrollo posterior de esta materia en Francia una total desnaturalización progresiva de las Leyes Aubry. Las sucesivas leyes laborales del gobierno Sarkozy, muy activo y virulento en el plano social contra los derechos e instituciones de 
los trabajadores, minaron la efectividad de los mecanismos planteados 10 años antes, erosionando gravemente la conquista parcial de las 35 horas. Asimismo, hemos podido ver que no ha habido un cambio de tendencia en esta materia con la llegada de los «socialistas» al poder del Estado. Tras nuevas regulaciones que permiten la anulación de facto del contenido de las Leyes Aubry - por "acuerdo" a nivel de empresa—, en la actualidad el proyecto de Ley Trabajo o El Khomri es sin duda una nueva vuelta de tuerca en la flexibilización del tiempo de trabajo diario y semanal, con las alteraciones que la misma implican en la resolución de los cuidados en el ámbito de los hogares y su peor reparto entre hombres y mujeres sometidos a marcos laborales sectorial y vitalmente muy diferenciados.

A la espera de ver como se resuelve el pulso social y sindical a esta nueva contrarreforma regresiva de los derechos del trabajo, hemos concluido con un balance positivo de esta experiencia, considerada una referencia en la conquista de mayores cotas de productividad «en especie» vía la RTT. Estando cualquier experiencia plagada de contradicciones, podemos afirmar que las Leyes Aubry dan buena fe de la vigencia histórica de las políticas de RTT a favor de los trabajadores y de un reparto más justo de los excedentes productivos y sus mejoras técnicas y organizativas permanentes. Así mismo, se considera que la reducción generalizada, sustantiva, equitativa y redistributiva del tiempo de trabajo (De la Fuente y Zubiri, 2016a) es la única vía creíble para afrontar la ineludible reorganización de los trabajos reproductivos y de cuidados, en la línea de su reparto consistente entre hombres y mujeres. Avancemos colectivamente por este camino.

\section{Bibliografía}

Albarracín Sánchez, Daniel (2003): De la utopía postindustrial a la crisis de las sociedades salariales de servicios: En torno al ciclo del capital y la identidad de clase de los trabajadores españoles en el capitalismo tardío, Tesis Doctoral dirigida por Luis Enrique Alonso Benito, Madrid, UCM, 638 p.

Alonso, Luis Enrique y PÉrez Ortiz, Lourdes (1996): ¿Trabajo para todos?: Un debate necesario, Madrid, Ediciones Encuentro, 140 p.

Álvarez Peralta, Nacho, Luengo, Fernando y Uxó, Jorge (2013): Fracturas y crisis en Europa, Madrid, Clave Intelectual, 342 p.

Amar, Michel et Prost, Corinne (2011): "Les évolutions de l'emploi et des salaires depuis 1990 ", Emploi et Salaires, édition 2011, INSEE, 19-38.

Arriola, Joaquín y Vasapollo, Luciano (2003): Flexibles y Precarios: La opresión del trabajo en el nuevo capitalismo europeo, Barcelona, El Viejo Topo.

Arrizabalo Montoro, Xabier (2014): Capitalismo y Economía Mundial: Bases teóricas y análisis empírico para la comprensión de los problemas económicos del siglo XXI, Madrid, Instituto Marxista de Economía, 720 p. 
Artus, Patrick, Cahuc, Pierre y Zylberberg, André (2007): Temps de travail, revenu et emploi, Rapport du Conseil d'Analyse Economique (CAE), n. ${ }^{\circ}$ 68, París.

Askenazy, Philippe (2007): Temps de travail: nouvelles propositions, vieux débats, http:// www.laviedesidees.fr

- (2013): «Working time regulation in France from 1996 to 2012», Cambridge Journal of Economics, disponible en http://cje.oxfordjournals.org/

Badinter, Robert (2016): Rapport au Premier ministre Comité chargé de définir les principes essentiels du droit du travail, Paris, Hôtel de Matignon, Janvier, 12 p.

BArbier, Jean Claude (2009): «Réformes du marché du travail: raison garder», Paris, Revue Esprit, n. ${ }^{\circ} 352$, janvier 2009, pp. 95-109.

Baron, Xabier: «Fin des 35 heures, fin d'un droit inutile?», Metis-correspondences européennes du travail.

BengoetxeA, Aitor (2016): «Régimen jurídico básico de las materias directamente vinculadas a la reducción del tiempo de trabajo", Lan Harremanak, n. ${ }^{\circ} 34,2016$ (1).

BÉroud, Sophie (2016), «Imposture de la démocratie d'entreprise», Le Monde Diplomatique, avril, 4-5. [Traducción: «La impostura de la democracia en la empresa», Manu Robles-Arangiz Fundazioa].

BÉroud, Sophie et Bouffartigue, Paul (2009) (dir.): Quand le travail se précarise, quelles résistances collectives?, Paris, Éditions La Dispute.

Boulin, Jean-Ives(2008): «Vers une politique européenne du temps de travail?», Metis-correspondences européenes du travail, 15 diciembre.

Castrillón Serna, Verónica, Zendoia Sainz, Jose Mari y Zubiri Rey, Jon Bernat (2016a): «Diagnóstico del empleo en Gipuzkoa», Lan Harremanak. Revista de Relaciones Laborales, n. ${ }^{\circ}$ 34, 2016 (1).

- (2016b): «Distribución funcional de la renta y costes laborales en Gipuzkoa: un estudio empírico para la reducción del tiempo de trabajo». Lan Harremanak. Revista de Relaciones Laborales, n. ${ }^{\circ}$ 34, 2016 (1).

- (2016c): «Indicadores socio-laborales de viabilidad por sectores de una reducción del tiempo de trabajo en Gipuzkoa», Lan Harremanak. Revista de Relaciones Laborales, n. ${ }^{\circ}$ 34, 2016 (1).

- (2016d): «Propuestas de reducción del tiempo de trabajo en Ggipuzkoa», Lan Harremanak. Revista de Relaciones Laborales, n. ${ }^{\circ}$ 34, 2016 (1)

Cahuc, Pierre, Carcillo, Stéphane y Zylberberg, André (2014): «Désinformation parlementaire sur les 35 heures", Les Échos, 22-12.

Carbonier, Clément, Palier, Bruno et Zemmour, Michaël (2015): «Faut-il remettre en question les baisses de cotisations sociales ? Contributions de Yannick L'Horty et Jean-Luc Tavernier. Réactions de Christophe Caresche et Alain Lambert», Débats du LIEPP n. ${ }^{\circ}$ 2, octobre 2015, 23 p.

- (2014): «Exonérations ou investissement social ? Une évaluation du coût d'opportunité de la stratégie française pour l'emploi», LIEPP Working Paper, n. ${ }^{\circ} 34$, novembre 2014, 46 p.

Carrasco Cristina, Borderías, Cristina y Torns, Teresa (2011): El trabajo de cuidados: historia, teoría y políticas, Colección «Economía Crítica \& Ecologismo Social», Madrid, CIP-Ecosocial y La Catarata, 411 p.

Cette, Gilbert y Taddei, Dominique (1997): Réduire la durée du travail. De la théorie à la pratique, Le Livre de Poche, París.

DARES (2003): "Les 35 heures dans les très petites entreprises», Premières Informations, Premières Synthèses, n. ${ }^{\circ}$ 46, 1-8. 
Daune-Richard, Anne-Marie (2007): "Las mujeres y la sociedad salarial: una investigación a partir de los casos de Francia, Reino Unido y Suecia», en AA.VV (Carlos Prieto, ed.), Trabajo, género y tiempo social, Hacer Editorial-Editorial Complutense, 242-266.

De la Fuente Lavín, Mikel (2000): «Un comentario sobre la Ley «Aubry» II del tiempo de trabajo en Francia», Sistema, núm. 157, 33-65.

De la Fuente Lavín, Mikel y Zubiri Rey, Jon Bernat (2016a): «Significado histórico y actualidad de las políticas de reducción del tiempo de trabajo", Lan Harremanak. Revista de Relaciones Laborales, n. ${ }^{\circ}$ 34, 2016 (1)

Delaveau, Bertille (2009): «Faut-il rééquilibrer le partage de la valeur ajoutée et des profits en faveur des salariés?», Centre d'analyse stratégique, La note de veille, n. ${ }^{\circ} 133$.

ELA (2015a): "Análisis de coyuntura», n. ${ }^{\circ} 129$, Manu Robles-Arangiz Institutua, septiembre 2015, 14 p.

- (2015b): "Análisis de coyuntura», n. ${ }^{\circ}$ 128, Manu Robles-Arangiz Institutua, julio 2015, 12 p.

Enjuto Jareño, Diego (2005): «La modificación de la Directiva 2003/88/CE: problemática en torno a la cláusula "opt-out», al período de referencia para el cómputo de la jornada ordinaria al concepto de «tiempo de trabajo efectivo», IUS Labor 3/2005.

Euzeby, Alain (2000): «Loi Aubry II sur les 35 heures: l'allègement des cotisations sociales patronales et l'emploi», Problèmes économiques, n. ${ }^{\circ} 2.672$, 5 juillet, pp. 3-8.

Fernández Durán, Ramón y González Reyes, Luis (2015): En la espiral de la energía. Tomo II: Colapso del capitalismo global y civilizatorio, Madrid, Libros en Acción y Baladre, $209 \mathrm{p}$.

Foray, Dominique (2009) : L'économie de la connaissance, Ed. La Découverte : collection Repères, Paris, $112 \mathrm{p}$.

Foulon, Sandrine (2014): «La fin des 35 heures, les entreprises n'en veulent pas», Alternatives Economiques, 29 de agosto, disponible en http://www.alternatives-economiques. fr

GARZón, Eduardo (2015): «Experiencia francesa de reducción de la jornada laboral», La Marea, n. ${ }^{\circ} 29$.

Gasté, Catherine (2016): «Comme la loi El Khomry va pénaliser les femmes», Le Parisien, 13-3-2016.

GonZÁlez SÁnchez, José Juan (1999): «La reducción del tiempo de trabajo en Francia: la ley de 13 de junio de 1998 y normas de desarrollo: balance y nuevo proyecto de ley de 1999", RTSS-CEF, núm. 199.

Harribey, J-M.: «Rapport Badinter: le diable est dans le premier article», La lettre d'Attac, 28-1-2016.

Husson, Michel (2004): «A nouveau les 35 heures», Regards, octobre

- (2010): «Le partage de la valeur ajoutée en Europe», Revue Internationale de l'Ires, n. ${ }^{\circ} 1,47-91$.

- (2012): "A la source de la crise : la baisse de la part salariale ", Colloque La distribution des richesses. Quelle part au salaire?, Bruxelles, ULB, 5 octobre 2012.

- (2015): «35 heures bashing», AlterEcoPlus, 15-1.

- (2016): «France. Réduction du temps de travail et chômage: trois scénarios», $\dot{A}$ l'encontre: La Brèche, 8 p.

Jany-Catrice, Florence et Puissant, Emmanuelle (2010), «L'aide à domicile face aux services à la personne et registres d'action contradictoires : des politiques aux organisations», Revue de l'IRES, n. ${ }^{\circ} 64,2010 / 1$. 
JEAN, Sébastien (2000): «Emploi: les enseignements de l'expérience néerlandaise», Économie et Statistique, n. ${ }^{\circ} 332-333,2000-2 / 3$, pp. 153-157.

Kessler, Denis (2012): «Il est temps d'abolir les 35 heures», Le Monde, 31-12.

KolÉDA, Gilles (2015): Allégements du coût du travail : pour une voie favorable à la compétitivité française, Paris, Presses des Mines et La Fabrique de l'industrie, $132 \mathrm{p}$.

Morini, Cristina (2014): Por amor o por la fuerza. Feminización del trabajo y biopolitica del cuerpo, Madrid, Traficantes de Sueños, 223 p. Descargable en http://www. traficantes.net

Labeaga, José María (2015): «La capacidad redistributiva del IRPF», El País Negocios, 2510-2014, 56.

Lordon, Fréderic (2008): Jusqu'à quand?: Pour en finir avec les crises financières. Paris, Raison d'Agir .Traducción: 2009. El porqué de las crisis financieras y cómo evitarlas. Madrid, CIP-Ecosocial y La Catarata.

Orozco, Amaia (2014): Subversión feminista de la economía, Madrid, Traficantes de Sueños. Descargable en http://www.traficantes.net/

Rodríguez Álvarez, Arantxa y Esteban Galarza, Marisol (2009) : «Innovación, creatividad y territorios inteligentes", Ciudad y territorio: Estudios territoriales, n. ${ }^{\circ} 159$, pp. 9-30.

Romagnan, Barbara (2014): "Commission d'enquête sur l'impact sociétal, social, économique et financier de la réduction progressive du temps de travail», Rapport à l'Assemblée nationale, Paris, 9 décembre 2014.

SAPIR, Jacques (2009) : "Depuis 30 ans, les salaires baissent, sauf au sommet», Marianne, Mardi 15 Décembre 2009.

SENS (2008): «La reduction collective du tempos de travail: un entretien avec Philippe Askenazy avec l'exemple des 35 heures», disponible en http://ses.ens-lyon.fr/lareduction-collective-du-temps-de-travail-un-entretien-avec-philippe-askenazy-avec-lexemple-des-35-heures-47479.kjsp

Solidaires (2016): «La loi travail, du sur-mesure pour le patronat !», Union Syndicale Solidaires, 29-2-2016.

Supiot, Alain (dir.) (1998): Transformation du travail et devenir du droit du travail en Europe. Conclusions du rapport, Comisión Europea, Luxemburgo.

VISSER, Jelle (2000): «La réduction du temps de travail aux Pays-Bas», Économie internationale la revue du CEPII, n. ${ }^{\circ} 83$, $3^{\text {éme }}$ trimestre, pp.129-152.

Zendoia Jose Mari; Ansa, Maite; Bengoetxea, Aitor; Castrillón, Veronica; De la Fuente, Mikel y Zubiri, Jon Bernat (2015): "Reparto del empleo y del tiempo de trabajo: Efectos en la fiscalidad y tratamiento jurídico", Informe de restitución de la investigación financiada por la Diputación Foral de Gipuzkoa, 313 p.

Zubiri Rey y Jon Bernat (2014): «El empleo juvenil como vector de transformación de las sociedades salariales de servicios», Boletín ECOS del Cip-Ecosocial, n.o 27, junio 2014, 15 p.

- (2011): «Precariedad, movimientos de huelga y sindicalismo en Francia», Encrucijadas. Revista critica de ciencias sociales, n. ${ }^{\circ} 1$, pp. 70-90.

- (2009): «La Renta de Solidaridad Activa en Francia. ¿Es la activación una vía para salir de la pobreza ?», Zerbitzuan, n. ${ }^{\circ} 45$, pp. 23-38. 